\title{
Management affects the pollinator abundance but not the reproductive success of butterfly orchids
}

\author{
Marilin Mõtlep (i) $\cdot$ Kadri Tali $\cdot$ Aigi Ilves $・$ Erki Õunap $\cdot$ Tiiu Kull
}

Received: 16 February 2018/ Accepted: 16 September 2018/Published online: 20 September 2018

(C) The Author(s) 2018

\begin{abstract}
Management of semi-natural grasslands should be based on the requirements of plants as well as their pollinators since conditions beneficial for plants are not necessarily beneficial for their pollinators and vice versa. The factors affecting the reproductive success (fruit set) of Platanthera bifolia and Platanthera chlorantha and their pollinators in agricultural landscape and woodlands were studied. In the years 2014-2016, we observed and caught moths during the flowering period of Platanthera species (late June-mid July) in four pure $P$. bifolia, five pure $P$. chlorantha and nine mixed populations under management or no management in Estonia. We determined pollinator species richness, pollinator abundance, fruit set and visibility of Platanthera plants in each population. We found that pollinator assemblages of $P$. bifolia and $P$. chlorantha did not differ between managed and unmanaged sites. Pollinator abundance had an effect on the fruit set of $P$. bifolia but not on that of $P$. chlorantha. Presence or
\end{abstract}

Communicated by Timothy Bell.

M. Mõtlep $(\varangle) \cdot$ K. Tali · A. Ilves · E. Õunap · T. Kull Institute of Agricultural and Environmental Sciences, Estonian University of Life Sciences, Kreutzwaldi 5, 51014 Tartu, Estonia

e-mail: marilin.motlep@emu.ee

E. Õunap

Institute of Ecology and Earth Sciences, University of

Tartu, Vanemuise 46, 51014 Tartu, Estonia absence of management, visibility of plants and rarefied pollinator species richness did not affect the fruit set of either plant species. Pollinator abundance was significantly higher in unmanaged populations of both plant species but rarefied pollinator species richness was higher only in unmanaged populations of $P$. chlorantha. Based on our findings the recommendations for management of semi-natural grasslands are to promote larger landscape diversity for the benefit of moth abundance by leaving unmanaged patches in different parts of a grassland in different years and rotational and post-fruiting management for higher reproductive success of orchids.

Keywords Moth pollination - Orchidaceae · Platanthera · Grassland · Grazing · Mowing

\section{Introduction}

In agricultural landscapes, semi-natural communities hold rich biodiversity important in various ways (Duelli and Obrist 2003). However, there has been a steady decline in the number and area of European semi-natural grasslands during the 20th century, mainly because of abandonment and afforestation (Henle et al. 2008; Poschlod and WallisDeVries 2002). The disappearance of small to medium-sized farms is one of the reasons why semi-natural 
grasslands are gradually overgrowing into forests (Nilsson et al. 2013). The absence of traditional management allows vegetation succession to run its natural course and grassland areas with nearby forests return to woodland (Hansson and Fogelfors 2000). Nowadays, a number of conservation methods are available for the restoration and maintenance of grassland habitats. The effect of conservation methods on pollinators and their food plants needs to be investigated further to establish the best means of management for diverse grasslands.

Management for conservation purposes should be based on the requirements of plants as well as their pollinators. A key issue is that moth populations benefit from a semi-natural environment with tall vegetation where moths can find more food, shelter and protection from predators (Fuentes-Montemayor et al. 2011; Kuussaari et al. 2007; Öckinger et al. 2006). Increased tree and bush coverage is also beneficial for moth species richness (Kuussaari et al. 2007); however, in such conditions managementdependent plants species decrease (Öckinger et al. 2006). Such conditions are also adverse for $P$. chlorantha and P. bifolia, as they lose out in competition with taller grasses.

Lepidoptera and orchids are valuable bioindicators. The presence of orchids is considered to be an indicator of ecosystem health and functionality (Swarts and Dixon 2009). Moths, being important pollinators and an essential part of the food chain, are also valuable indicators (Warren and Bourn 2011), primarily due to short generation time and quick response to environmental change (Erhardt and Thomas 1991). Moths are also suitable indicators of restoration success in semi-natural grasslands (Pöyry et al. 2005; Rákosy and Schmitt 2011). Butterfly orchids (Platanthera) which can be found in seminatural habitats in Estonia are in a close mutualistic relationship with their pollinators-moths (Nilsson 1983); hence, it is an appropriate pair to concentrate on while studying the effects of management on biodiversity. Pollinators can play an important role in the distribution of plant species since plant traits and reproductive success could be affected by pollinators' physiology, ecology and behaviour (Sargent and Ackerly 2008).

Semi-natural habitats are mainly managed by mowing and grazing which according to several contradictory reports from different authors affect pollinators and their food plants diversely. It has been found that livestock density negatively affects moth abundance and species richness (Tadey 2015; Littlewood 2008). Pollinators seem to benefit from abandonment (Pöyry et al. 2004) or late grazing regime which favours taller vegetation and higher flower abundance (Sjödin 2007). However, other authors have found no differences in butterfly abundance and species richness in grazed and abandoned pastures (Elwell et al. 2016; Sjödin et al. 2008; Öckinger et al. 2006) but butterfly species richness has been found to increase with increasing vegetation height (Öckinger et al. 2006).

Fruit set (the proportion of flowers which have developed into fruits) of $P$. bifolia and $P$. chlorantha varies to a great extent between years and populations (Kindlmann and Jersáková 2006; Maad 2000; Maad and Alexandersson 2004; Nilsson 1983; Vojtkó et al. 2015) and is generally pollinator limited (Maad and Alexandersson 2004). While Mróz (2006) found no difference in fruit set between managed meadows and unmanaged road verges, Nakahama et al. (2016) detected a negative effect of mowing during JulySeptember on fruit set.

The aim of this study was to find out which factors play a role in the reproductive success (fruit set) of $P$. bifolia and $P$. chlorantha and affect their pollinators in semi-natural and woodland habitats. We asked (1) if presence or absence of management affect pollinator assemblages, pollinator abundance and pollinator species richness in $P$. bifolia and $P$. chlorantha populations, (2) if the presence or absence of management, visibility of plants, pollinator abundance and pollinator species richness affect the reproductive success of Platanthera species. Additionally, we aimed to find out whether and to which extent fruit set differs between the two Platanthera species and between mixed and pure populations of each species.

\section{Materials and methods}

\section{Study species}

Sister species Platanthera bifolia (L.) L. C. Rich. and $P$. chlorantha (Custer) Rchb. are terrestrial orchids with a Eurasian distribution (Hultén and Fries 1986). Platanthera chlorantha is not distributed as far north as $P$. bifolia, and its distribution is more fragmented 
(Hultén and Fries 1986). In Estonia, P. bifolia is more widely distributed, growing with low densities mainly in lighter forests, wooded meadows and wooded pastures, whereas $P$. chlorantha can also be found in alvar grasslands. Both species produce 10-20 white hermaphroditic flowers with a nectariferous spur. The flowers emit a sweet fragrance that attracts nocturnal pollinators. In Scandinavia, $P$. bifolia is known to be pollinated by forest specialist species of Sphingidae and $P$. chlorantha by open habitat specialist species of Noctuidae (Nilsson 1983). The plant species differ in flower morphology: $P$. bifolia has a narrow column with parallel anther pockets, $P$. chlorantha has a wider column with anther pockets at an angle. Anther pocket positioning within the flower of $P$. bifolia results in pollinia attaching to the base of the pollinator's proboscis (Nilsson 1983), while in P. chlorantha, the pollinia attach to the eyes of the pollinator (Nilsson 1978).

\section{Study sites}

We focused on four pure Platanthera bifolia, five pure $P$. chlorantha and nine mixed populations in both managed and unmanaged sites in Estonia (Fig. 1). The study started in 2014 when observations were made in six populations. In 2015, four new populations were visited and in 2016, observations were made in eight new populations (Table 1). Semi-natural grasslands (alvars, meadows, wooded meadows and wooded pastures) under study were divided into two types based on their management scheme: (1) grasslands which had been annually managed for at least 5 years, (2) grasslands where management had been neglected for at least 10 years. Since butterfly orchids were not found in completely overgrown semi-natural habitats, these areas were not included in our study. We chose populations growing in areas where management had been neglected but at least some plants had still survived so that fruit set could be determined. Woodland populations were also included as a comparison with abandoned sites (see Fig. 1). Platanthera plants were the main food plants for pollinators in the populations under observation.

\section{Data collection}

For determining pollinator species, we observed and caught moths in every population. Observations were made from 22:00 until 00:00 $\mathrm{h}(\mathrm{GMT}+2)$, one night per population during the flowering period of Platanthera species (late June-mid July). We chose calm nights with air temperature above $13{ }^{\circ} \mathrm{C}$ and no precipitation for maximum moth activity. Nights with such weather conditions were scarce during flowering seasons and for that reason we did not make observations for more than one night per population. Moth species visiting the inflorescences (pollinator species richness) were recorded. Pollinator abundance was estimated as the sum of individuals observed pollinating and carrying pollinia as well as individuals carrying pollinia caught with light trap per population. To catch additional pollinators, we used a light trap with a $250 \mathrm{~W}$ clear mercury vapour lamp, which was switched on from 00:00 until 02:00 h. Caught moths carrying pollinia and/ or who had been previously observed pollinating were considered as pollinators. In mixed populations, moths carrying pollinia on their proboscises (Fig. 2a) were considered pollinators of $P$. bifolia and moths with pollinia attached to their eyes (Fig. 2b) were considered pollinators of $P$. chlorantha according to previous studies (Nilsson 1978, 1983). The composition of pollinator assemblage was thus determined both by observation and a light trap (similarly to Tadey 2015). For determining reproductive success, we counted the flowers and fruits of at least 15 plants (in smaller populations all the plants were included) and calculated the proportion of flowers which developed into fruits (fruit set). In each population, we determined visibility: if the surrounding vegetation was dominating and concealing Platanthera plants potentially rendering them hidden from pollinators the visibility was marked with 'No' and when clearly visible with 'Yes'.

\section{Statistical analysis}

To test for the effects of the presence and the absence of management on pollinator community composition, we used permutation-based multivariate analysis of variance (PERMANOVA). Bray-Curtis distance measure and 4999 random permutations were used. We also tested for multivariate homogeneity of group dispersions. As a result of the distance based dispersion test and permutation test, assumption of homogeneity was met for the $P$. bifolia pollinator community but not for the $P$. chlorantha pollinator community. We used the non-metric multidimensional scaling (NMDS) test to visualise managed and 


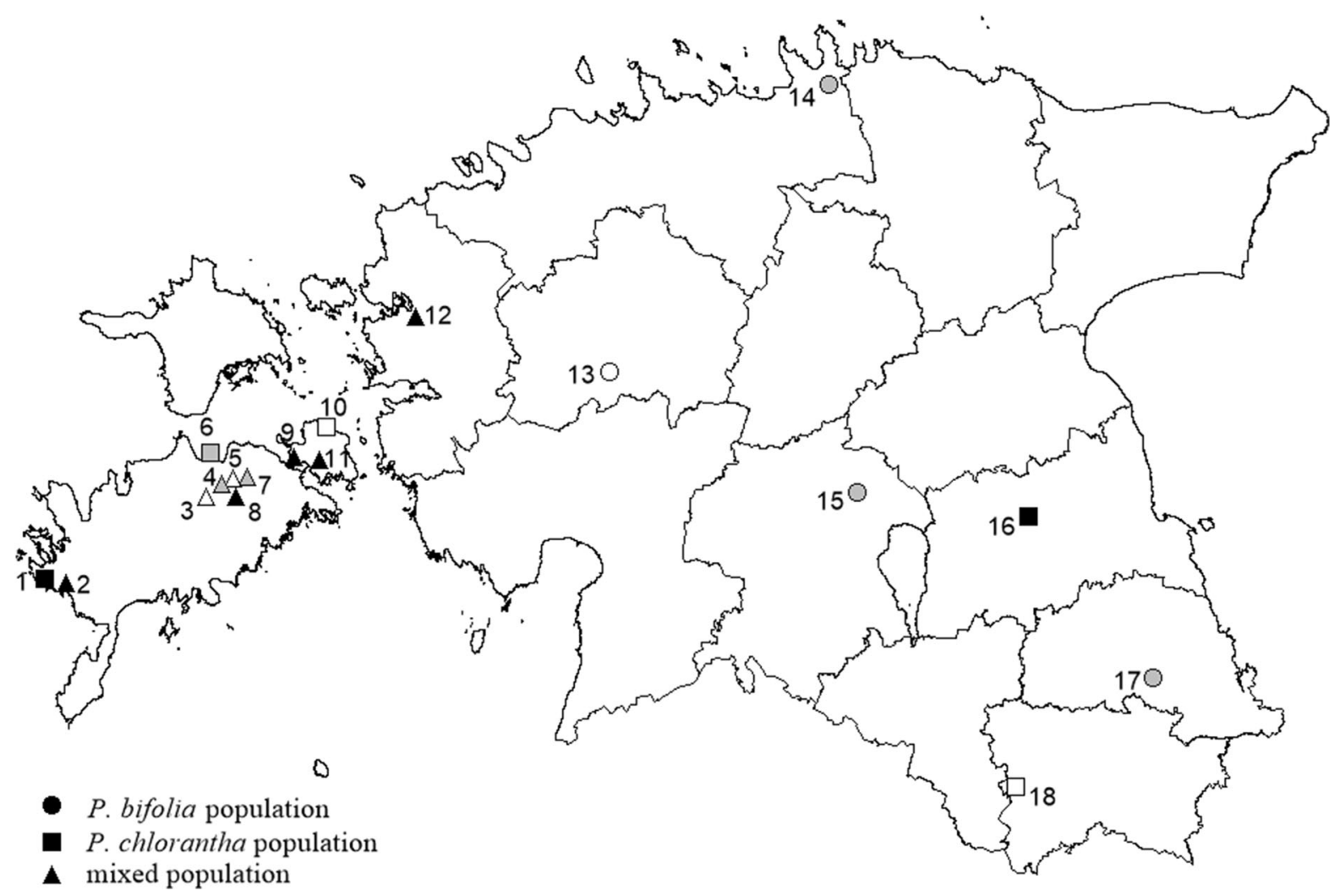

Fig. 1 Location and type of habitat of study sites in Estonia. Filled black symbols indicate continuously managed grasslands, filled grey symbols indicate woodlands and unfilled symbols indicate abandoned grasslands. Populations: 1-Karala, 2-

unmanaged sites in species space. Again, the BrayCurtis statistic was used as the measure of ordination distance among pollinator communities.

We used the $t$ test to compare fruit set, pollinator abundance and pollinator species richness and the Mann-Whitney $U$ test to compare the visibility of plants between abandoned and woodland populations. Since no differences were found, the data of these populations were pooled.

We used GLM with Gaussian distribution to test the effects of management, visibility, pollinator abundance and pollinator species richness on fruit set. Prior to the analysis, a logit transformation was performed on the fruit set data according to the recommendations of Warton and Hui (2011). Visibility was treated as a binary variable (yes/no). Abundance-based rarefaction method was used on pollinator species richness data. GLMs with Poisson distributions were used to
Pilguse, 3-Tutku, 4-Pärsama, 5-Nihatu, 6-Patimaja, 7Väike-Pahila, 8-Ratla, 9-Koguva, 10-Peedu, 11-Ridasi, 12-Laheva, 13-Vana-Nurtu, 14-Kotka, 15-Parika, 16Vorbuse, 17-Süvahavva, 18-Küünimetsa

analyse the effects of management on pollinator abundance and pollinator species richness of each Platanthera species separately. Additionally, we tested if the area of the sites under observation and population size had an effect on the fruit set, pollinator abundance and pollinator species richness but no effect was found. Populations where no pollinators were observed or caught were not included in the analysis.

To compare the fruit set between Platanthera species and between mixed and pure populations of each species, the $t$ test was used as the data were normally distributed.

All tests were performed using $\mathrm{R}$ version 3.3.2 (2016-10-31). 
Table 1 Characteristics of study populations of Platanthera bifolia and $P$. chlorantha in Estonia
${ }^{\mathrm{a}}$ Fruit set is the proportion of flowers which developed into fruits

${ }^{\mathrm{b}}$ Visibility is marked with 'Yes' when plants were not concealed by surrounding vegetation and were visible to pollinators from a distance, and 'No' in the opposite situation

\begin{tabular}{|c|c|c|c|c|c|}
\hline Population & Species & Year & Fruit set $\pm \mathrm{SD}^{\mathrm{a}}$ & Visibility $^{\mathrm{b}}$ & Population size \\
\hline Vana-Nurtu & P. bifolia & 2014 & $71.3 \pm 24.0$ & No & 5 \\
\hline Süvahavva & P. bifolia & 2014 & $30.3 \pm 35.2$ & Yes & 10 \\
\hline Kotka & P. bifolia & 2015 & $94.0 \pm 6.9$ & Yes & 100 \\
\hline Parika & P. bifolia & 2015 & $91.0 \pm 11.7$ & Yes & 100 \\
\hline Vorbuse & P. chlorantha & 2015 & $9.9 \pm 11.3$ & Yes & 10 \\
\hline Karala & P. chlorantha & 2016 & $88.9 \pm 15.4$ & Yes & 25 \\
\hline Küünimetsa & P. chlorantha & 2014 & $42.8 \pm 27.9$ & No & 25 \\
\hline Peedu & P. chlorantha & 2015 & $23.6 \pm 16.5$ & Yes & 25 \\
\hline Patimaja & P. chlorantha & 2014 & $77.2 \pm 13.5$ & Yes & 25 \\
\hline Koguva & $\begin{array}{l}\text { P. bifolia } \\
\text { P. chlorantha }\end{array}$ & 2014 & $\begin{array}{l}31.0 \pm 9.3 \\
0\end{array}$ & No & $\begin{array}{l}50 \\
50\end{array}$ \\
\hline Laheva & $\begin{array}{l}\text { P. bifolia } \\
\text { P. chlorantha }\end{array}$ & 2016 & $\begin{array}{l}89.1 \pm 9.5 \\
89.0 \pm 13.1\end{array}$ & Yes & $\begin{array}{r}5 \\
25\end{array}$ \\
\hline Ridasi & $\begin{array}{l}\text { P. bifolia } \\
P . \text { chlorantha }\end{array}$ & 2016 & $\begin{array}{l}87.3 \pm 1.3 \\
69.8 \pm 22.5\end{array}$ & No & $\begin{array}{l}5 \\
5\end{array}$ \\
\hline Pilguse & $\begin{array}{l}\text { P. bifolia } \\
\text { P. chlorantha }\end{array}$ & 2016 & $\begin{array}{l}0 \\
79.6 \pm 17.2\end{array}$ & Yes & $\begin{array}{r}5 \\
25\end{array}$ \\
\hline Ratla & $\begin{array}{l}\text { P. bifolia } \\
P . \text { chlorantha }\end{array}$ & 2016 & $\begin{array}{l}38.9 \pm 7.9 \\
79.8 \pm 19.5\end{array}$ & Yes & $\begin{array}{l}10 \\
10\end{array}$ \\
\hline Tutku & $\begin{array}{l}\text { P. bifolia } \\
\text { P. chlorantha }\end{array}$ & 2016 & $\begin{array}{l}66.7 \pm 5.6 \\
79.9 \pm 30.5\end{array}$ & No & $\begin{array}{r}5 \\
10\end{array}$ \\
\hline Nihatu & $\begin{array}{l}\text { P. bifolia } \\
\text { P. chlorantha }\end{array}$ & 2016 & $\begin{array}{l}80.1 \pm 18.1 \\
66.7 \pm 57.7\end{array}$ & Yes & $\begin{array}{r}25 \\
5\end{array}$ \\
\hline Pärsama & $\begin{array}{l}\text { P. bifolia } \\
\text { P. chlorantha }\end{array}$ & 2014 & $\begin{array}{l}69.1 \pm 39.0 \\
69.9 \pm 14.9\end{array}$ & Yes & $\begin{array}{l}25 \\
25\end{array}$ \\
\hline Väike-Pahila & $\begin{array}{l}\text { P. bifolia } \\
\text { P. chlorantha }\end{array}$ & 2016 & $\begin{array}{l}55.0 \pm 42.4 \\
86.1 \pm 16.8\end{array}$ & Yes & $\begin{array}{l}10 \\
10\end{array}$ \\
\hline
\end{tabular}

\section{Results}

Pollinator assemblages

\section{Platanthera bifolia}

In total, three moth species and 28 specimens were considered as pollinators of $P$. bifolia during the study. Pollinators were observed and/or caught in eight populations (three managed and five unmanaged) and the main pollinators were Sphinx ligustri and $S$. pinastri (Table 2). No pollinators were found in five populations (three managed and two unmanaged).

Solution in NMDS with stress $<0.05$ was reached. In Fig. 3a, the NMDS ordination based on pollinator species and their abundances is presented. It shows that managed and unmanaged sites overlapped somewhat, an unmanaged and managed population were overlapping, as were two unmanaged sites. The result of PERMANOVA was statistically insignificant $(P=0.72)$, so there was no difference between managed and unmanaged sites in pollinator composition.

\section{Platanthera chlorantha}

In 13 sites, a total of 14 moth species and 65 specimens were considered as pollinators of $P$. chlorantha during the study. In The main pollinators of $P$. chlorantha belonging to families Noctuidae (11 species) and Sphingidae (three species) and their abundances across all sites are presented in Table 2. In one unmanaged population, no pollinators were found. 


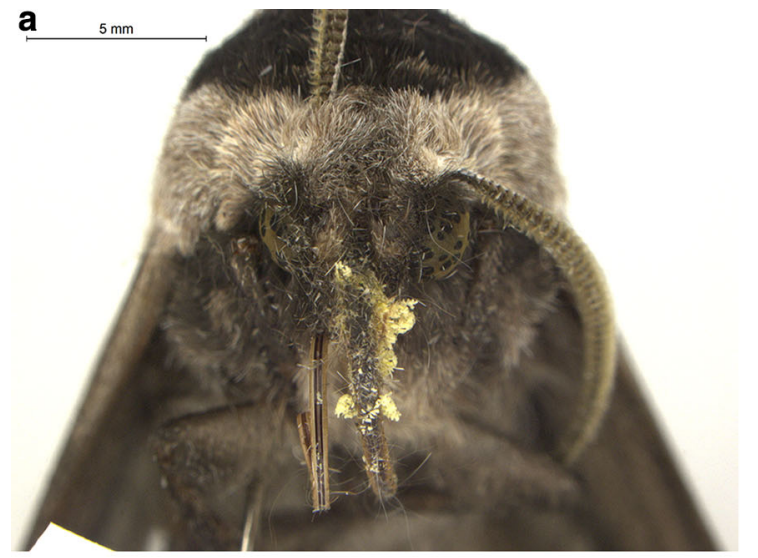

b

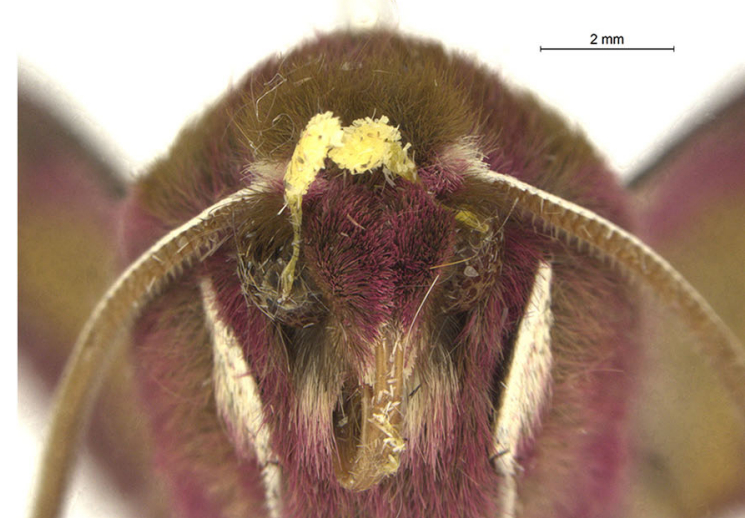

Fig. 2 Sphinx ligustri carrying the pollen of Platanthera bifolia (a) and Deilephila porcellus with pollinia of P. chlorantha (b)

Stress for NMDS solution was 0.05. The NMDS ordination showed that managed sites were more sparsely distributed in the plot suggesting that they had a low degree of similarity, while unmanaged sites showed greater similarity but were situated within the managed sites species space (Fig. 3b). The result from the PERMANOVA statistical analysis showed that the pollinator community compositions in managed and unmanaged sites were not significantly different $(P=0.13)$

Different factors influencing fruit set

GLM showed that pollinator abundance had an effect on the fruit set of $P$. bifolia but not in $P$. chlorantha (Table 3). Fruit set of either plant species was not affected by the presence or the absence of management, visibility of plants and rarefied pollinator species richness.
The effect of management on pollinator abundance and pollinator species richness

GLM showed that pollinator abundance was significantly higher in unmanaged populations of both plant species. Rarefied pollinator species richness was higher in unmanaged populations of $P$. chlorantha but did not differ between managed and unmanaged populations of $P$. bifolia (Table 4).

Comparison of fruit set between species and between mixed and pure populations

Fruit set did not differ statistically between $P$. bifolia and $P$. chlorantha in 2014 (means 50.4\% and 36.7\%, respectively, $P=0.48$ ) and 2016 (means $59.6 \%$ and $80.0 \%$, respectively, $P=0.15$ ). We could not test for differences in 2015 because there were only two sites for each species under observation that year. The fruit set of mixed and pure populations of $P$. chlorantha did not differ (means $69.0 \%$ and $39.8 \%$ respectively, $P=0.11$ ), neither did the fruit set of mixed and pure populations of $P$. bifolia (means $57.5 \%$ and $71.7 \%$ respectively, $P=0.45$ ).

\section{Discussion}

Our study revealed that only a few moth species pollinate Platanthera bifolia but their abundance could play an important role in the reproductive success of the plant species. P. chlorantha, in contrast, is pollinated by many moth species; however, the reproductive success of the plant species may not be dependent on pollinator abundance. While this study did not demonstrate any effect of the presence or the absence of management on Platanthera species, pollinator abundance was higher in unmanaged sites. However, as we made observations for one night per population, our results need to be confirmed by further research.

Both moths and orchids probably benefit from a certain degree of abandonment, for moths more abandonment could be favourable because taller vegetation provides them more food and shelter, post-fruiting or rotational management could benefit orchids because mowing or grazing at the end of their vegetation period or no management every other year allows the plants to flower and set fruit. 
Table 2 List of pollinator species of $P$. bifolia and $P$. chlorantha observed and/or caught during the study and their abundances across all sites

\begin{tabular}{|c|c|c|c|}
\hline Plant species & Pollinator species & Family & Abundance \\
\hline \multirow[t]{3}{*}{ P. bifolia } & Sphinx pinastri & Sphingidae & 16 \\
\hline & Sphinx ligustri & Sphingidae & 10 \\
\hline & Deilephila elpenor & Sphingidae & 2 \\
\hline \multirow[t]{14}{*}{ P. chlorantha } & Autographa jota & Noctuidae & 14 \\
\hline & Diachrysia stenochrysis & Noctuidae & 9 \\
\hline & Abrostola tripartita & Noctuidae & 6 \\
\hline & Autographa pulchrina & Noctuidae & 5 \\
\hline & Hadena bicruris & Noctuidae & 4 \\
\hline & Apamea monoglypha & Noctuidae & 3 \\
\hline & Autographa gamma & Noctuidae & 3 \\
\hline & Noctua pronuba & Noctuidae & 3 \\
\hline & Diachrysia chrysitis & Noctuidae & 2 \\
\hline & Autographa bractea & Noctuidae & 1 \\
\hline & Xestia baja & Noctuidae & 1 \\
\hline & Sphinx pinastri & Sphingidae & 12 \\
\hline & Deilephila porcellus & Sphingidae & 1 \\
\hline & Hyles gallii & Sphingidae & 1 \\
\hline
\end{tabular}

Pollinator assemblages

In accordance with earlier findings of Nilsson $(1978,1983)$ and Boberg et al. (2014) in Scandinavia, we also found that the main pollinators of Platanthera bifolia belonged to the Sphingidae family and pollinators of $P$. chlorantha to the Noctuidae family in Estonia. Pollinator assemblages of $P$. bifolia did not differ between managed and unmanaged sites. The main pollinators Sphinx ligustri and S. pinastri were found in both habitat types. This result was expected because the managed sites (wooded meadows) and unmanaged ones (abandoned wooded meadows and woodlands) are both suitable habitats for hawk moths.

Pollinator community composition of P. chlorantha also did not differ between managed and unmanaged sites but unmanaged sites showed greater similarity to each other than managed sites. Most of the pollinator species caught during this study prefer open habitats with the exception of $S$. pinastri. Although it is considered a woodland species (Pavlikova and Konvicka 2012), we found S. pinastri also in a managed site.

Different factors influencing fruit set

Pollinator abundance had an effect on the fruit set of Platanthera bifolia. The more pollinators within the insect population, the more flowers are potentially pollinated and this results in higher fruit set (Amorim et al. 2014; Lowenstein et al. 2015; Petanidou et al. 2013). However, this effect did not appear in $P$. chlorantha which could be explained by low moth activity in observation nights. Presence or absence of management did not affect the fruit set of either Platanthera species. This result is in accordance with the study of Mróz (2006) who found no differences in fruit set between managed and unmanaged populations of Colchicum autumnale. To the best of our knowledge, other than the previously mentioned study, there are practically no studies that have examined differences in fruit set between managed and unmanaged habitats. Absence of management influences orchid populations, as after several seasons the increasing layers of litter may restrict seedling emergence and establishment (Schrautzer et al. 2011). Although moths preferably respond to scent (Balkenius et al. 2006), it could be assumed that in unmanaged grasslands it is more difficult for pollinators to detect flowering plants due to surrounding and dominating vegetation as visual stimuli give them direction (Nilsson 1978). However, in our study, visibility of plants did not affect the fruit set of either study species. Rarefied pollinator species richness also had no effect on the fruit set of either Platanthera species which could be explained by the fact that 

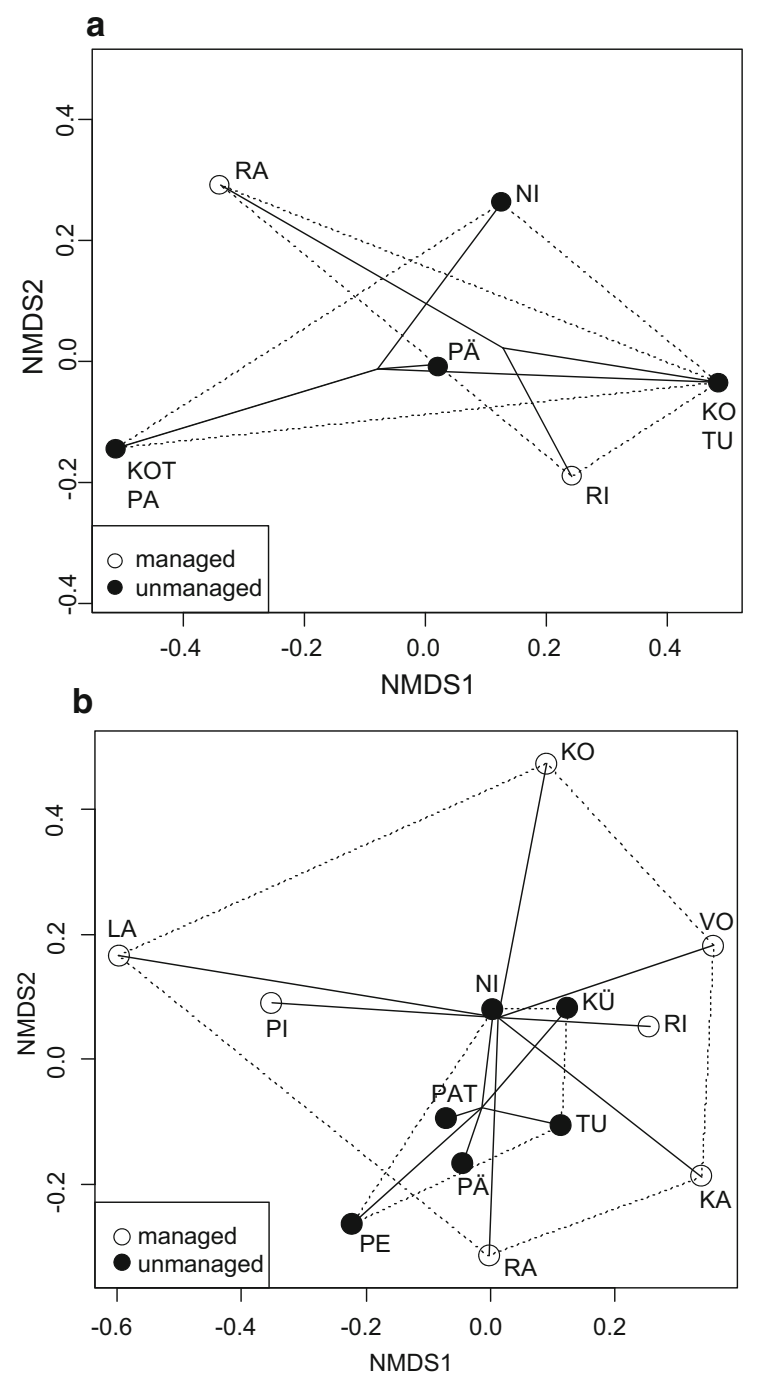

Fig. 3 Non-metric multidimensional scaling (NMDS) of managed and unmanaged sites in $P$. bifolia (a) and $P$. chlorantha (b) pollinator species space. In case of $P$. bifolia, an unmanaged (Tutku) and managed (Koguva) population overlap, as do two unmanaged sites (Parika and Kotka). In case of $P$. chlorantha, managed sites are more sparsely distributed and therefore less similar than unmanaged sites which are situated in the managed sites species space. Population abbreviations: $R A$ Ratla, $N I$ Nihatu, $P \ddot{A}$ Pärsama, $K O$ Koguva, $T U$ Tutku, KOT Kotka, $P A$ Parika, RI Ridasi, LA Laheva, VO Vorbuse, PI Pilguse, $K \ddot{U}$ Küünimetsa, $P A T$ Patimaja, KA Karala, $P E$ Peedu

pollinator species of $P$. bifolia and P. chlorantha are all nocturnal moths, they share feeding times and pollinate in the same way, so only a few moth species may be sufficient pollinators in a population. However, other authors (Klein et al. 2003; Lowenstein et al. 2015; Mallinger and Gratton 2015) have had contrary results with flower-visiting bees where species richness increased the fruit set of study plants. One explanation for these contrasting results is that different bee species forage at different times during the flowering season and therefore complement each other in pollination.

The effect of management on pollinator abundance and pollinator species richness

Pollinator abundance of both Platanthera species was significantly higher in unmanaged populations. Our results are in accordance with previous studies which have found that moth abundance is higher in abandoned and unmanaged grasslands (Littlewood 2008; Pöyry et al. 2004). Rarefied pollinator species richness was significantly higher in the unmanaged sites of $P$. chlorantha but pollinator species richness of $P$. bifolia does not seem to be affected by either management or abandonment, as previous authors have shown (Elwell et al. 2016; Öckinger et al. 2006; Sjödin et al. 2008). However, in contrast to our results, these authors also showed that pollinator abundance is similar in managed and unmanaged grasslands. Moths prefer taller vegetation (Sjödin 2007) and higher flower abundance (Kuussaari et al. 2007; Pöyry et al. 2004, 2009; Sjödin 2007), conditions which are present in unmanaged grasslands and this could explain why in our study, pollinator abundance was higher in unmanaged sites. However, in the absence of management at some point, grasses start to dominate and flower abundance decreases which in turn is disadvantageous for moth pollinators. We could not select sites with such a degree of abandonment because all the orchids had long since died out by then (see former note in "Study sites"). We did not see pollinators in five populations of $P$. bifolia and in one $P$. chlorantha population but in most of these sites fruit set was quite high. Since moths, especially sphingids, are able to fly distances of several kilometres (Merckx et al. 2009) it could be that a random passer-by was responsible for high fruit set. Tałałaj et al. (2017) showed that though autogamy is possible in $P$. bifolia, it however did not occur in bagged plants. The high fruit set in some of our study sites therefore cannot be explained as a result of spontaneous autogamy. 
Table 3 Factors determining the fruit set of $P$. bifolia and $P$. chlorantha based on GLM

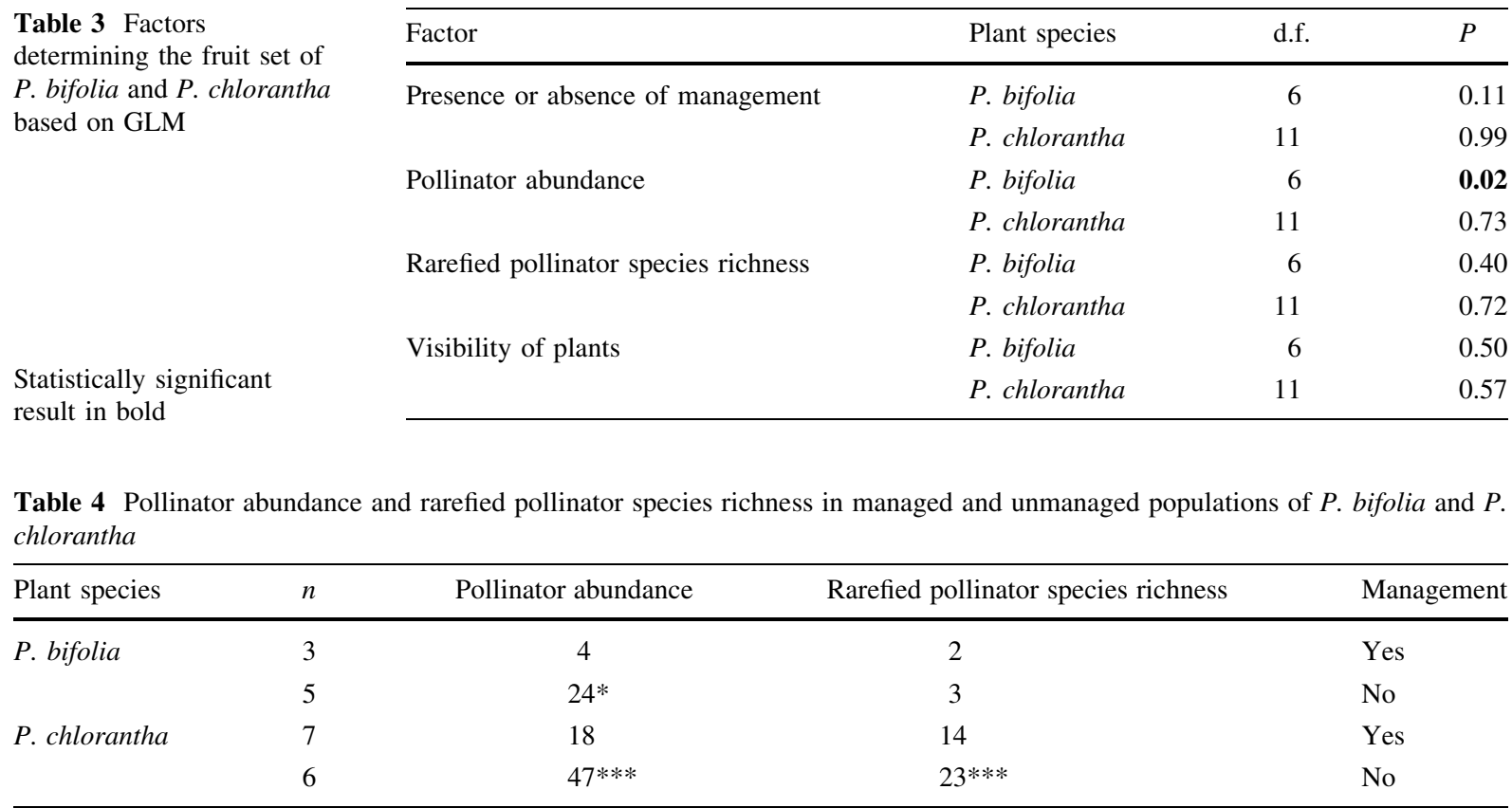

Statistically significant result in bold

$* P<0.05 ; * * * P<0.001$

Comparison of fruit set between species and between mixed and pure populations

Fruit set varied to a great extent between years but was mostly rather similar between our study species irrespective of the fact that the number of pollinator species differed greatly between the studied plant species (three in $P$. bifolia and 14 in $P$. chlorantha). Our research showed that the fruit set of $P$. bifolia and $P$. chlorantha did not differ in the study years. In all study years, the fruit sets of both species were in the range of fruit sets reported by other authors (Kindlmann and Jersáková 2006; Maad 2000; Maad and Alexandersson 2004; Nilsson 1983; Vojtkó et al. 2015). The similarity in fruit set between the plant species with a contrastingly different number of pollinator species shows again that pollinator species richness does not seem to affect the reproductive success of butterfly orchids and in fact pollinator abundance may be of key importance, as several authors have shown in other plant species (Amorim et al. 2014; Lowenstein et al. 2015; Petanidou et al. 2013).

The fruit set of mixed and pure populations of either Platanthera species did not differ so neither plant species seems to benefit from growing together with the sister species.

\section{Conclusions}

Our study demonstrates that the pollinators of Platanthera bifolia and P. chlorantha, moth species belonging to families Sphingidae and Noctuidae, may be favoured by the absence of management as their abundance was higher in unmanaged sites compared to the managed ones. Fruit set of $P$. bifolia, in turn, seems to benefit from higher pollinator abundance; however, in $P$. chlorantha, pollinator abundance had no effect on fruit set and the fruit set of neither Platanthera species was affected by the presence or the absence of management in this study. Based on our findings, the recommendations for management of semi-natural grasslands are to promote larger landscape diversity for the benefit of moth abundance by leaving unmanaged patches in different parts of a grassland in different years and rotational and postfruiting management at the end of August for higher reproductive success of orchids. 
Acknowledgements The study was supported by institutional research funding (IUT 20-33 and IUT 21-1) of the Estonian Ministry of Education and Research, herbarium TAA and the entomological collection at the Institute of Agricultural and Environmental Sciences, Estonian University of Life Sciences (IZBE).

\section{Compliance with ethical standards}

Conflict of interest The authors declare that they have no conflict of interest.

Open Access This article is distributed under the terms of the Creative Commons Attribution 4.0 International License (http:// creativecommons.org/licenses/by/4.0/), which permits unrestricted use, distribution, and reproduction in any medium, provided you give appropriate credit to the original author(s) and the source, provide a link to the Creative Commons license, and indicate if changes were made.

\section{References}

Amorim FW, Wyatt GE, Sazima M (2014) Low abundance of long-tongued pollinators leads to pollen limitation in four specialized hawkmoth-pollinated plants in the Atlantic Rain forest, Brazil. Naturwissenschaften 101(11):893-905

Balkenius A, Rosén W, Kelber A (2006) The relative importance of olfaction and vision in a diurnal and a nocturnal hawkmoth. J Comp Physiol A 192(4):431-437

Boberg E, Alexandersson R, Jonsson M, Maad J, Ågren J, Nilsson LA (2014) Pollinator shifts and the evolution of spur length in the moth-pollinated orchid Platanthera bifolia. Ann Bot 113(2):267-275

Duelli P, Obrist MK (2003) Regional biodiversity in an agricultural landscape: the contribution of seminatural habitat islands. Basic Appl Ecol 4(2):129-138

Elwell SL, Griswold T, Elle E (2016) Habitat type plays a greater role than livestock grazing in structuring shrubsteppe plant-pollinator communities. J Insect Conserv 20:515-525

Erhardt A, Thomas JA (1991) Lepidoptera as indicators of change in the semi-natural grasslands of lowland and upland Europe. In: Collins NM, Thomas JA (eds) The conservation of insects and their habitats. Academic Press, London, pp 213-236

Fuentes-Montemayor E, Goulson D, Park KJ (2011) The effectiveness of agri-environment schemes for the conservation of farmland moths: assessing the importance of a landscape-scale management approach. J Appl Ecol 48(3):532-542

Hansson M, Fogelfors H (2000) Management of a semi-natural grassland; results from a 15-year-old experiment in southern Sweden. J Veg Sci 11(1):31-38

Henle K, Alard D, Clitherow J, Cobb P, Firbank L, Kull T, McCracken D, Moritz RFA, Niemelä J, Rebane M, Wascher D, Watt A, Young J (2008) Identifying and managing the conflicts between agriculture and biodiversity conservation in Europe-a review. Agric Ecosyst Environ 124(1-2):60-71
Hultén E, Fries M (1986) Atlas of North European vascular plants: north of the tropic of cancer, vol 1. Koeltz Scientific Books, Königstein

Kindlmann P, Jersáková J (2006) Effect of floral display on reproductive success in terrestrial orchids. Folia Geob 41:47-60

Klein A, Steffan-Dewenter I, Tscharntke T (2003) Fruit set of highland coffee increases with the diversity of pollinating bees. Proc Royal Soc B 270(1518):955-961

Kuussaari M, Heliölä J, Luoto M, Pöyry J (2007) Determinants of local species richness of diurnal Lepidoptera in boreal agricultural landscapes. Agric Ecosyst Environ 122(3):366-376

Littlewood NA (2008) Grazing impacts on moth diversity and abundance on a Scottish upland estate. Insect Conserv Divers 1(3):151-160

Lowenstein DM, Matteson KC, Minor ES (2015) Diversity of wild bees supports pollination services in an urbanized landscape. Oecologia 179(3):811-821

Maad J (2000) Phenotypic selection in hawkmoth-pollinated Platanthera bifolia: targets and fitness surfaces. Evolution 54(1):112-123

Maad J, Alexandersson R (2004) Variable selection in Platanthera bifolia (Orchidaceae): phenotypic selection differed between sex functions in a drought year. J Evol Biol 17(3):642-650

Mallinger RE, Gratton C (2015) Species richness of wild bees, but not the use of managed honeybees, increases fruit set of a pollinator-dependent crop. J Appl Ecol 52(2):323-330

Merckx T, Feber RE, Dulieu RL, Townsend MC, Parsons MS, Bourn NAD et al (2009) Effect of field margins on moths depends on species mobility: field-based evidence for landscape-scale conservation. Agric Ecosyst Environ 129(1):302-309

Mróz L (2006) Variation in stage structure and fitness traits between road verge and meadow populations of Colchicum autumnale (Liliaceae): effects of habitat quality. Acta Soc Bot Pol 75(1):69-78

Nakahama N, Uchida K, Ushimaru A, Isagi Y (2016) Timing of mowing influences genetic diversity and reproductive success in endangered semi-natural grassland plants. Agric Ecosyst Environ 221:20-27

Nilsson LA (1978) Pollination ecology and adaptation in Platanthera chlorantha (Orchidaceae). Bot Not 131:35-51

Nilsson LA (1983) Processes of isolation and introgressive interplay between Platanthera bifolia (L.) Rich. and $P$. chlorantha (Custer) Reichb. (Orchidaceae). Bot J Linn Soc 87:325-350

Nilsson SG, Franzén M, Pettersson LB (2013) Land-use changes, farm management and the decline of butterflies associated with semi-natural grasslands in southern sweden. Nat Conserv 6:31-48

Öckinger E, Eriksson AK, Smith HG (2006) Effects of grassland abandonment, restoration and management on butterflies and vascular plants. Biol Conserv 133(3):291-300

Pavlikova A, Konvicka M (2012) An ecological classification of Central European macromoths: habitat associations and conservation status returned from life history attributes. J Insect Conserv 16(2):187-206

Petanidou T, Duffy KJ, Karatza A, Kantsa A (2013) Reduced fecundity in large populations of a Mediterranean orchid- 
evidence for pollinator limitation. Basic Appl Ecol 14(1):36-43

Poschlod P, WallisDeVries MF (2002) The historical and socioeconomic perspective of calcareous grasslands-lessons from the distant and recent past. Biol Conserv 104(3):361-376

Pöyry J, Lindgren S, Salminen J, Kuussaari M (2004) Restoration of butterfly and moth communities in semi-natural grassland by cattle grazing. Ecol Appl 14(6):1656-1670

Pöyry J, Lindgren S, Salminen J, Kuussaari M (2005) Responses of butterfly and moth species to restored cattle grazing in semi-natural grasslands. Biol Conserv 122(3):465-478

Pöyry J, Paukkunen J, Heliölä J, Kuussaari M (2009) Relative contributions of local and regional factors to species richness and total density of butterflies and moths in seminatural grasslands. Oecologia 160(3):577-587

Rákosy L, Schmitt T (2011) Are butterflies and moths suitable ecological indicator systems for restoration measures of semi-natural calcareous grassland habitats? Ecol Indic 11(5):1040-1045

Sargent RD, Ackerly DD (2008) Plant-pollinator interactions and the assembly of plant communities. Trends Ecol Evol 23(3): 123-130

Schrautzer J, Fichtner A, Huckauf A, Rasran L, Jensen K (2011) Long-term population dynamics of Dactylorhiza incarnata
(L.) Soó after abandonment and re-introduction of mowing. Flora-Morphol Distrib Funct Ecol Plants 206(7):622-630

Sjödin NE (2007) Pollinator behavioural responses to grazing intensity. Biodivers Conserv 16:2103-2121

Sjödin NE, Bengtsson J, Ekbom B (2008) The influence of grazing intensity and landscape composition on the diversity and abundance of flower-visiting insects. J Appl Ecol 45(3):763-772

Swarts ND, Dixon KW (2009) Terrestrial orchid conservation in the age of extinction. Ann Bot 104(3):543-556

Tadey M (2015) Indirect effects of grazing intensity on pollinators and floral visitation. Ecol Entomol 40(4):451-460

Tałałaj I, Ostrowiecka B, Włostowska E, Rutkowska A, Brzosko E (2017) The ability of spontaneous autogamy in four orchid species: Cephalanthera rubra, Neottia ovata, Gymnadenia conopsea, and Platanthera bifolia. Acta Biol Crac s. Bot 59(2):51-61

Vojtkó AE, Sonkoly J, Lukács BA, Molnár VA (2015) Factors affecting reproductive success in three entomophilous orchid species in Hungary. Acta Biol Hung 66(2):231-241

Warren MS, Bourn NAD (2011) Ten challenges for 2010 and beyond to conserve Lepidoptera in Europe. J Insect Conserv 15:321-326

Warton DI, Hui FKC (2011) The arcsine is asinine: the analysis of proportions in ecology. Ecology 92(1):3-10 